\title{
Do the Relative Mapping Densities of the Magno- and Parvocellular Systems Vary with Eccentricity?
}

\author{
Margaret S. Livingstone and David $\mathbf{H}$. Hubel \\ Department of Neurobiology, Harvard Medical School, Boston, Massachusetts 02115
}

\begin{abstract}
Two recent papers on the macaque visual system have concluded that in the lateral geniculate body the ratio of the number of cells in the magnocellular system to the number in the parvocellular system representing the same area of visual field increases by a factor of 20 between the fovea and the far periphery. In the primary visual cortex the relative cell densities of the 2 systems change little with eccentricity. These calculations therefore predict a 20-fold change in the relative densities of the inputs to the visual cortex from the 2 subdivisions of the lateral geniculate body.

To test this prediction, we asked if the following vary with eccentricity: (1) the ratio of the number of magnocellular to parvocellular neurons innervating a given area of striate cortex and (2) the relative density, in the magno- and parvorecipient sublaminae of layer $\mathbf{4 C}$, of radioactivity transported from the eye to the cortex. Neither of these ratios showed any significant variation with eccentricity. These results seem to throw doubt on the contention that the ratio between the magnocellular and parvocellular layers of the number of cells per degree ${ }^{2}$ of visual field varies significantly with eccentricity.
\end{abstract}

The primate visual system consists of 2 functionally and anatomically distinct subdivisions. This subdivision was first seen in the lateral geniculate bodies, which have 2 obviously different kinds of layers: the cells in the ventral, or magnocellular, layers are larger than the cells in the dorsal, parvocellular, layers. Though most obvious in the geniculate, this split in the visual pathway does not arise there - the 2 geniculate subdivisions receive input from 2 anatomically and physiologically distinct types of retinal ganglion cells. The larger, Type A, ganglion cells project to the magnocellular layers, and the smaller, Type B, project to the parvocellular layers (Leventhal et al., 1981). This functional segregation is maintained in the primary visual cortex: the magnocellular division innervates the upper half of layer $4 \mathrm{C}, 4 \mathrm{C} \alpha$, and the parvocellular layers innervate the lower half, $4 \mathrm{C} \beta$ (Hubel and Wiesel, 1972).

Cells in these 2 subdivisions also have very different visual response properties, suggesting that they subserve quite different

\footnotetext{
Received Jan. 22, 1988; revised Apr. 8, 1988; accepted Apr. 12, 1988.

Histology was done by Janet Robbins. The manuscript benefitted from comments from Simon LeVay, Joseph Malpeli, and David Van Essen. The work was supported by NIH Grants EY00605 and KO4 NS00972, a Presidential Young Investigator Award from the NSF, Office of Naval Research grant N00014-85$\mathrm{K}-0447$, a Young Investigator Award from the Office of Naval Research, and funds from the Monsanto Company.

Correspondence should be addressed to Margaret Livingstone at the above address.
}

Copyright (C) 1988 Society for Neuroscience $0270-6474 / 88 / 114334-06 \$ 02.00 / 0$ visual functions: parvocellular neurons are color selective, whereas magnocellular neurons are color-blind; magnocellular neurons have faster temporal resolution, higher contrast sensitivity, and lower spatial resolution than parvocellular neurons (for references and qualifications, see Livingstone and Hubel, 1987). In anatomical studies these 2 pathways show little interconnection (for discussion, see Lund, 1987), and their very different and characteristic visual response properties are consistent with their being largely independent.

Despite the fact that the 2 subdivisions seem to be in some ways separate and independent, they share the same visuotopic maps for at least the first 3 stages of visual information processing - the retina, the lateral geniculate bodies, and the first cortical visual area. At all 3 of these stages the number of cells devoted to a given size region of visual field decreases with distance from the fovea. This is accomplished in the retina by changes in thickness and cell packing of the ganglion-cell layer: in Visual Area 1 by a variation in the cortical area analyzing a given area of visual field and in the geniculate by both kinds of changes. In a recent paper, Connolly and Van Essen (1984) came to the surprising conclusion that in the geniculate the ratio of cells/(degree of visual field) ${ }^{2}$ for the fovea to cells/degree ${ }^{2}$ for the far periphery is 20 times higher in the parvo system than in the magno system. From evidence that the ratio of the number of retinal ganglion cells, (Type A plus Type B)/degree ${ }^{2}$, to the number of geniculate cells (magno- plus parvocellular)/degree ${ }^{2}$, is approximately 1 across the visual field, Schein and de Monasterio (1987) further concluded that the ratio of magno- to parvo-projecting retinal ganglion cells must also change with eccentricity, in the same manner predicted for the geniculate. Perry el al. (1984) directly examined Type A and Type B retinal ganglion cells and found that the Type A cells formed a constant $10 \%$ of the total from $10^{\circ}-50^{\circ}$ eccentricity, but unfortunately their measurements did not include the central $10^{\circ}$. In contrast, for Visual Area 1, Schein and de Monasterio concluded that the relative magno to parvo representation does not vary with eccentricity, on the basis of their own unpublished observations that the relative thicknesses of layers $4 C \alpha$ and $4 C \beta$ do not vary with eccentricity.

This assertion, that in the retina and in the geniculate the magno system, compared with the parvo system, is 20-fold underrepresented near the center of gaze, is important because it predicts that different visual abilities will vary quite differently as a function of eccentricity, depending on whether they are carried out by the magno or the parvo pathway. Such a prediction seems inconsistent with some recent evidence on human perception. For example, the functions specific to the magno system seem to include stereopsis, motion perception, and per- 
haps vernier hyperacuity, whereas high-resolution form perception seems to be carried by the parvo system (for review, see Livingstone and Hubel, 1987). A relative overrepresentation of the magno system in the periphery therefore predicts that stereopsis, movement perception, and vernier hyperacuity performance should decrease with eccentricity more slowly than, for example, grating acuity. In fact, exactly the reverse is found experimentally-stereopsis, movement perception, and vernier acuity all degrade faster with eccentricity than grating acuity or minimum resolvable angle (Westheimer, 1982; Fendick and Westheimer, 1983; McKee and Nakayama, 1984). We have therefore analyzed these 2 reports, as well as the evidence from other laboratories on which these reports were based, and have used orthograde and anterograde axonal transport to test their predictions more directly.

\section{Materials and Methods}

Retrograde labeling of geniculate neurons by horseradish peroxidase (HRP) injections in striate cortex. In each of 3 hemispheres from 2 young adult Macaque fascicularis monkeys we injected wheat-germ conjugated HRP at 3 locations: (1) the most lateral part of the operculum, $3 \mathrm{~mm}$ behind the lunate sulcus; (2) the medial border of the operculum, just above the calcarine fissure; and (3) various parts of the striate cortex buried in the calcarine sulcus. The monkeys were anesthetized first with ketamine, and then anesthesia was maintained throughout the injection procedure with $1.5 \%$ halothane in air. Burr holes about $3 \mathrm{~mm}$ in diameter were drilled in the skull and small holes cut in the dura. Wheatgerm conjugated HRP (Sigma) was dissolved in $0.1 \mathrm{M}$ Tris buffer, $\mathrm{pH}$ 8.6 , at a concentration of $15 \% \mathrm{wt} / \mathrm{vol}$ and injected iontophoretically through glass micropipettes with a tip diameter $20-40 \mu \mathrm{m}$, using a 1 $\mu \mathrm{A}$ square-wave current, electrode positive, $5 \mathrm{sec}$ on/ $10 \mathrm{sec}$ off, for 5 min. Survival times were $3 \mathrm{~d}$, after which the animals were anesthetized with sodium thiopental and perfused transcardially with 1 liter of physiological saline, followed by 1 liter of fixative $(0.75 \%$ paraformaldehyde, $2.25 \%$ glutaraldehyde, $0.9 \% \mathrm{NaCl}, 0.1 \mathrm{M}$ sodium phosphate buffer, $\mathrm{pH}$ 7.4). The location and the depth of the injections in the striate cortex were determined by sectioning the occipital lobe coronally on a freezing microtome, in $50 \mu \mathrm{m}$-thick sections, reacting alternate sections for cytochrome oxidase (Wong-Riley, 1979) or the method of Hanker et al. (1977) to reveal the HRP. The lateral geniculate body was cut coronally in $25-\mu$ m-thick sections, and the sections were reacted with the tetramethylbenzidine method of Mesulam (1982) to detect the HRP. Labeled cells were counted at 100 and $250 \times$ magnification.

Density of transsynaptic transport of tritiated amino acids from the eye. We measured the density of silver grains in layers $4 \mathrm{C} \alpha$ and $4 \mathrm{C} \beta$ at various eccentricities in Visual Area 1 of a $M$. fascicularis monkey that had been injected intraocularly with $2 \mathrm{mCi}$ of ${ }^{3} \mathrm{H}$-proline 14 and $18 \mathrm{~d}$

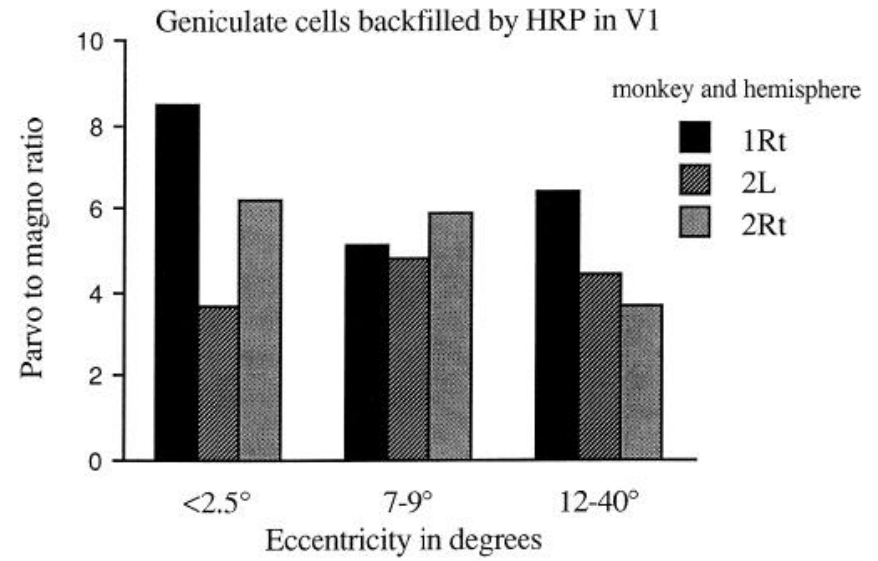

Figure 1. Ratio of the number of labeled cells in the parvocellular geniculate layers to the number in the magnocellular layers after HRP injections at various eccentricities in Visual Area 1. (1Rt refers to the right hemisphere of monkey 1 , etc.)

before perfusion. This is the same monkey that was used in the study of LeVay et al. (1985). Simon LeVay kindly provided us with 3 sections, each of which showed both the foveal representation and the far periphery. Photographs of the autoradiograms were enlarged 1400 times, and we counted the number of silver grains in $0.1 \times 0.15 \mathrm{~mm}$ areas centered on each of the 2 sublaminae of layer $4 \mathrm{C}$ in ocular dominance columns innervated by the injected eye. We counted 15-20 such areas $\left(5-7 /\right.$ section) in each of 4 regions, corresponding to $<1^{\circ}, 2-3^{\circ}, 10-20^{\circ}$, and $>40^{\circ}$ eccentricity.

Measurement of sublamina thickness in layer $4 C$. For 6 different eccentricities we enlarged photographs of autoradiograms such as those shown in Figure 2, in which the distinction between layers $4 \mathrm{C} \alpha$ and $4 \mathrm{C} \beta$ was clear, and in which the plane of section was approximately perpendicular to the surface. We measured the relative thicknesses of these 2 sublayers in at least 5 ocular dominance columns for each eccentricity.

\section{Results}

HRP injections into Visual Area 1

The very dark cores of our injections in the striate cortex were 2-5 $\mathrm{mm}$ in diameter, and, from maps of the representation of the visual field on the striate cortex (Daniel and Whitteridge, 1961; Van Essen et al., 1984), we determined that the 3 lateral injections corresponded to regions of the visual field less than

Table 1. Labeled cells in magnocellular and parvocellular LGN layers after HRP injections in V1

\begin{tabular}{|c|c|c|c|c|c|c|}
\hline \multirow{3}{*}{$\begin{array}{l}\text { Eccentricity of HRP } \\
\text { injection site in V1 }\end{array}$} & \multicolumn{6}{|c|}{$\begin{array}{l}\text { Number of cells } \\
\text { (parvo-to-magno ratio) }\end{array}$} \\
\hline & \multicolumn{2}{|c|}{$\begin{array}{l}\text { Monkey } 1 \\
\text { right hemisphere }\end{array}$} & \multicolumn{2}{|c|}{$\begin{array}{l}\text { Monkey } 2 \\
\text { left hemisphere }\end{array}$} & \multicolumn{2}{|c|}{$\begin{array}{l}\text { Monkey } 2 \\
\text { right hemisphere }\end{array}$} \\
\hline & parvo & magno & parvo & magno & parvo & magno \\
\hline \multirow[t]{2}{*}{$<2^{\circ}$} & 313 & 37 & 101 & 27 & 318 & 51 \\
\hline & \multicolumn{2}{|c|}{$(8.5)$} & \multicolumn{2}{|c|}{ (3.7) } & \multicolumn{2}{|c|}{$(6.2)$} \\
\hline \multirow[t]{2}{*}{$7^{\circ}-9^{\circ}$} & 200 & 39 & 334 & 70 & 182 & 31 \\
\hline & \multicolumn{2}{|c|}{ (5.1) } & \multicolumn{2}{|c|}{ (4.8) } & \multicolumn{2}{|c|}{$(5.9)$} \\
\hline \multirow[t]{2}{*}{$12^{\circ}-15^{\circ}$} & 847 & 132 & \multirow{2}{*}{\multicolumn{2}{|c|}{-}} & \multirow{2}{*}{\multicolumn{2}{|c|}{-}} \\
\hline & \multicolumn{2}{|c|}{$(6.4)$} & & & & \\
\hline \multirow[t]{2}{*}{$20^{\circ}-25^{\circ}$} & \multirow{2}{*}{\multicolumn{2}{|c|}{-}} & 84 & 19 & \multirow{2}{*}{\multicolumn{2}{|c|}{-}} \\
\hline & & & \multicolumn{2}{|c|}{ (4.4) } & & \\
\hline \multirow[t]{2}{*}{$30^{\circ}-40^{\circ}$} & \multirow{2}{*}{\multicolumn{2}{|c|}{-}} & \multirow{2}{*}{\multicolumn{2}{|c|}{-}} & 267 & 72 \\
\hline & & & & & \multicolumn{2}{|c|}{ (3.7) } \\
\hline
\end{tabular}




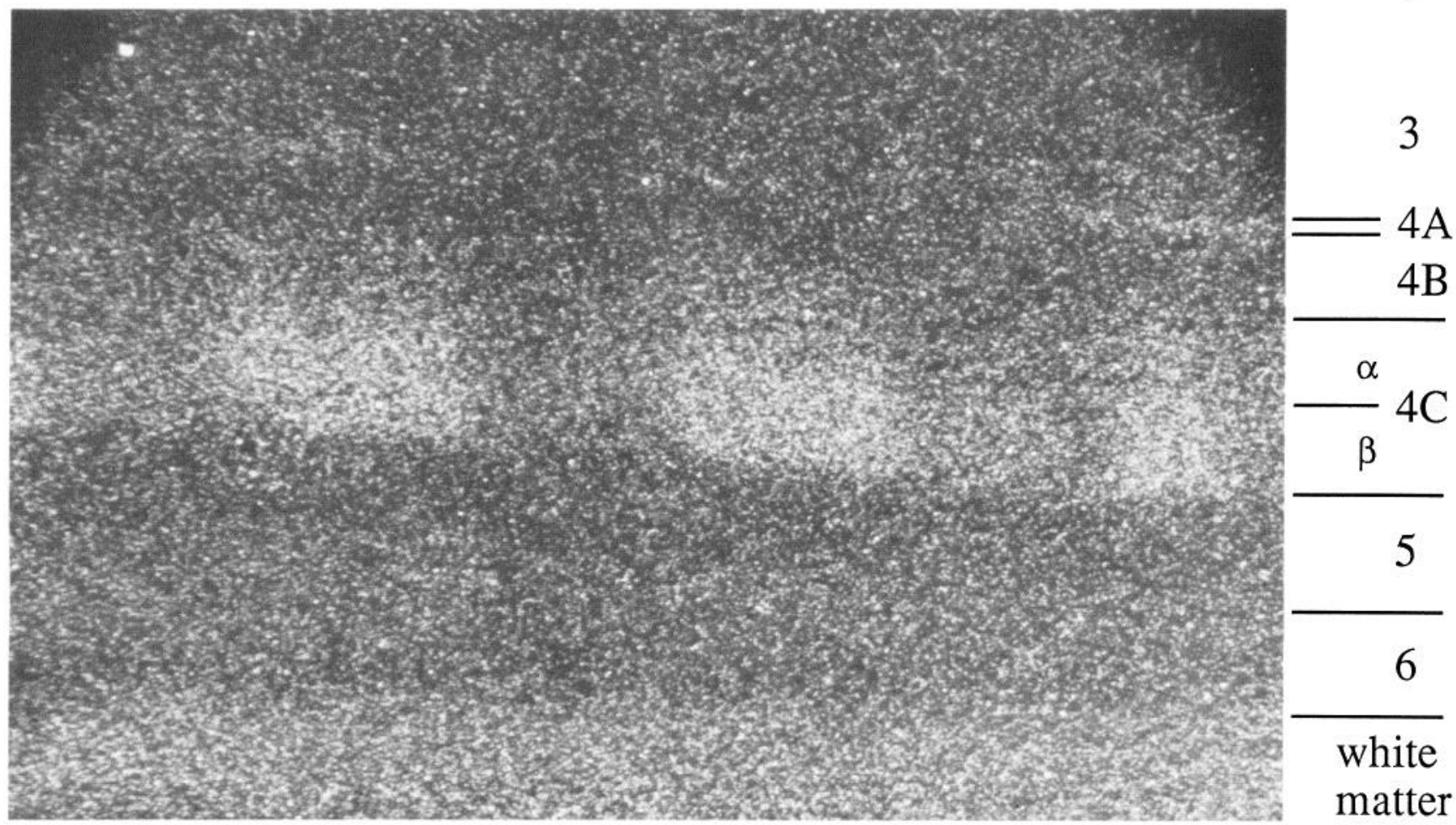

fovea $\left(<1^{\circ}\right)$

periphery $\left(>40^{\circ}\right)$

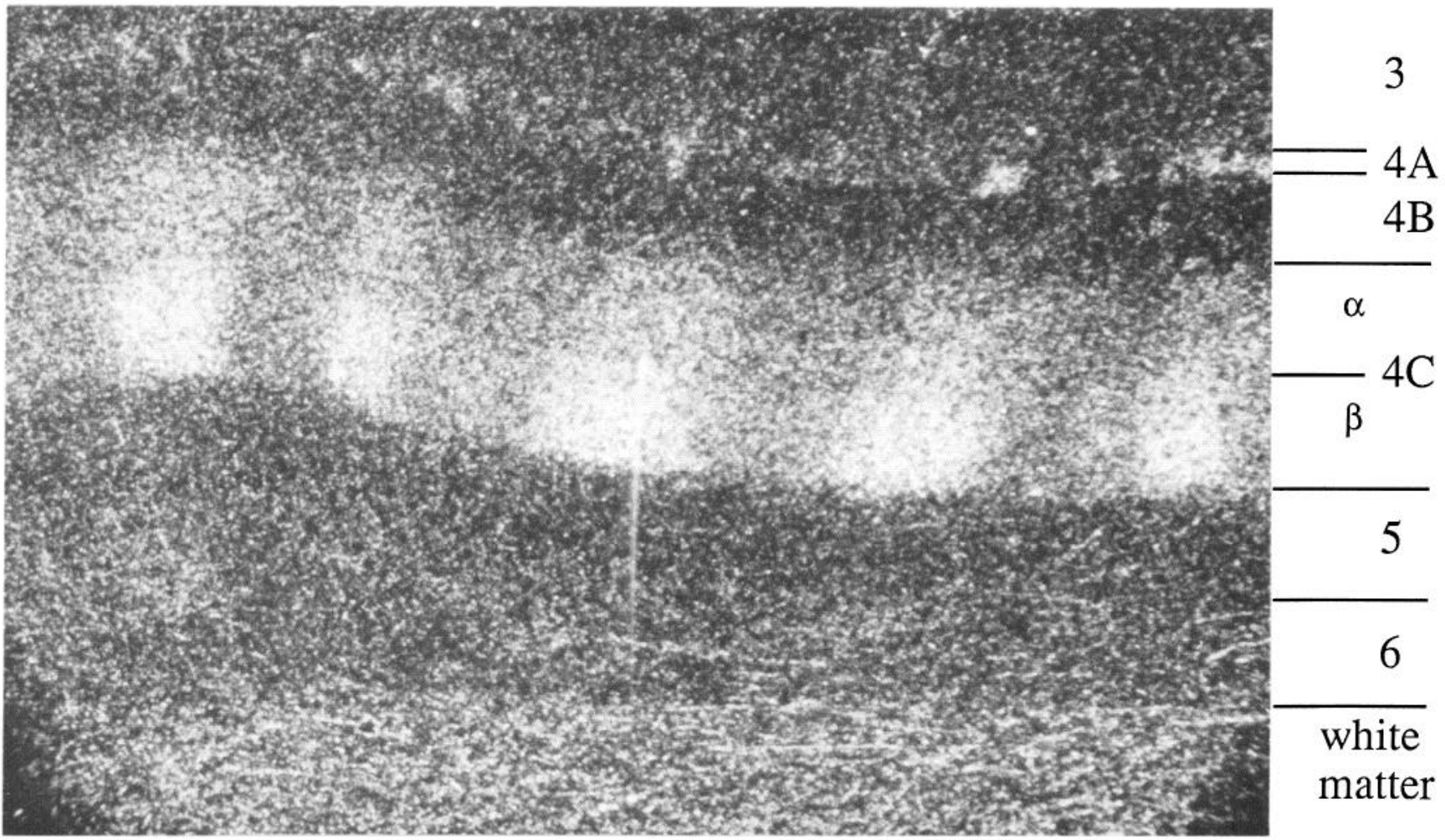

Figure 2. Autoradiogram of Visual Area 1 after injection of tritiated proline into one eye of a macaque (sections generously provided by Simon LeVay). Top, Foveal region, corresponding to $1^{\circ}$ or less eccentricity. Bottom, Region corresponding to the periphery of the visual field, more than $40^{\circ}$ eccentricity. Note that the overall labeling density is higher in the periphery, probably reflecting the change in magnification in going from the retina to the cortex. Note also that the ratios of the thicknesses of the 2 sublaminae of $4 \mathrm{C}$ are the same at these 2 eccentricities. 


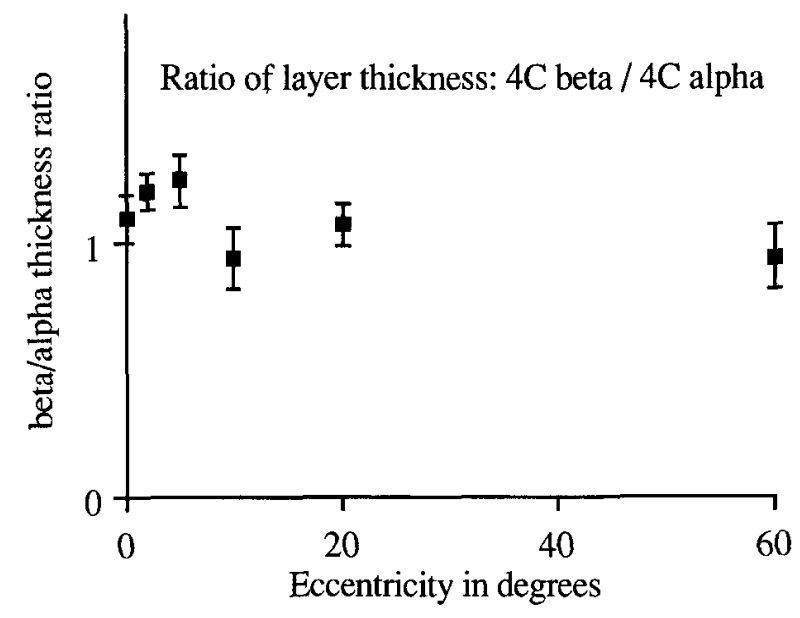

Figure 3. Graph of the ratio of the thickness of sublayer $4 \mathrm{C} \beta$ to $4 \mathrm{C} \alpha$ in Visual Area 1. We used autoradiograms such as those shown in Figure 2 , in which the 2 sublaminae were clearly distinct, to measure the relative thicknesses. Error bars represent the SE of the measurements. There is no significant variation with eccentricity.

$2^{\circ}$ from the center of gaze; the 3 injections in the operculum near the midline all corresponded to $7^{\circ}-9^{\circ}$ eccentricity; one calcarine injection was in the roof of the sulcus, corresponding to $12^{\circ}-15^{\circ}$ eccentricity; the second calcarine injection was in the lower shelf, corresponding to $20^{\circ}-25^{\circ}$ eccentricity; the third was in the stem of the sulcus, corresponding to $30^{\circ}-40^{\circ}$ eccentricity. For each injection we determined the ratio of labeled neurons in the magnocellular and parvocellular layers. The results are shown in Table 1 . These cell counts indicate that the ratio of parvocellular neurons to magnocellular neurons projecting to the same area of striate cortex is between 4 and 8 , and does not vary systematically with eccentricity. This is shown graphically in Figure 1.

\section{Tritiated-proline eye injections}

If, as Schein and de Monasterio have argued, the underrepresentation of the magno system relative to the parvo system originates in the retina, then this discrepancy in the 2 systems should be apparent on comparing, at different eccentricities, the relative density of transynaptic transport of tritiated amino acids from the eye to layers $4 \mathrm{C} \alpha$ and $4 \mathrm{C} \beta$ of the striate cortex, assuming that the transport of tritiated amino acid from the eye to any region of cortex is proportional to the number of retinal ganglion cells providing input to that region. Thus, if the ratio of parvo cells to magno cells in the retina and geniculate is higher in the fovea than in the periphery, then the ratio of the density of silver grains in $4 \mathrm{C} \beta$ to $4 \mathrm{C} \alpha$ should likewise be higher foveally.

Figure 2 shows 2 regions of an autoradiogram from a single tissue section. One region corresponds to the foveal representation and the other to $40^{\circ}$ eccentricity. The regions receiving input from the injected eye are clearly distinguishable, as are layers $4 \mathrm{C} \alpha$ and $4 \mathrm{C} \beta$. The results of our silver-grain counts are shown in Table 2. Between the foveal representation and $>40^{\circ}$ eccentricity the grain densities in both sublaminae vary 4 - to 5 -fold, probably reflecting the relative increase in foveal representation in going from the retina to the cortex. [The ratio of the number of ganglion cells/(degree of visual field) ${ }^{2}$ is about 100 times higher in the fovea than at $60^{\circ}$ eccentricity, whereas the area of striate cortex devoted to a degree ${ }^{2}$ varies almost

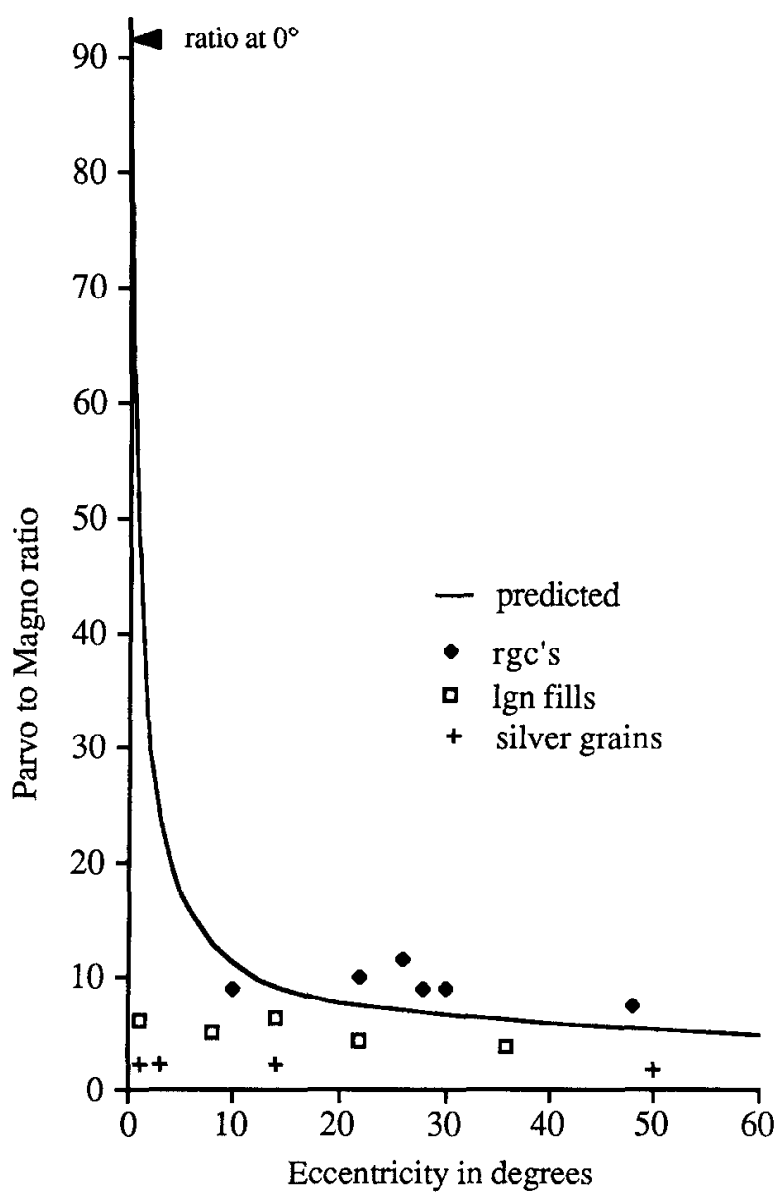

Figure 4. Comparison of 3 experimentally determined ratios of parvo to magno cells/degree ${ }^{2}$ with the relationship predicted by Schein and de Monasterio (1987). The open squares indicate our results for the ratio of parvocellular to magnocellular neurons innervating the same area of striate cortex, that is, the ratio of parvo- to magnocellular geniculate cells back-labeled by HRP injections in Visual Area 1. The crosses show the ratios of silver grain densities in layers $4 C \beta$ to $4 C \alpha$ after intraocular injection of triated proline. The diamonds are Perry et al.'s (1984) ratios of Type B to Type A retinal ganglion cells ( $r g c$ 's). The line shows the calculated ratio of the density of parvocellular and magnocellular neurons (Table 1 of Connolly and Van Essen, 1984; or equations 2 and 3 from Schein and de Monasterio, 1987). The change in the parvo-to-magno ratio with eccentricity predicted by the calculations of Connolly, Van Essen, Schein and de Monasterio is much steeper than any of the 3 more directly determined relationships.

1000-fold between $1^{\circ}$ and $60^{\circ}$ (Hubel and Freeman, 1977; Tootell et al., 1982; Perry et al., 1984; Schein, 1988).] The variation we see in total labeling indicates that the grain density probably does accurately reflect the relative innervation density. In contrast, the ratio of the number of grains in the 2 sublaminae does

Table 2. Average silver grain density (grains $/ 0.015 \mathrm{~mm}^{2}$ ) in the 2 sublaminae of layer $4 \mathrm{C}$ after ${ }^{3} \mathrm{H}$-proline eye injection

\begin{tabular}{lccl} 
Eccentricity & Layer $4 \mathrm{C} \alpha$ & Layer $4 \mathrm{C} \beta$ & $\frac{\text { Density in } 4 \mathrm{C} \beta}{\text { Density in } 4 \mathrm{C} \alpha}$ \\
\hline Fovea $\left(<1^{\circ}\right)$ & $348 \pm 34$ & $666 \pm 112$ & $1.9 \pm 0.77$ \\
$2^{\circ}-3^{\circ}$ & $517 \pm 62$ & $1097 \pm 105$ & $2.1 \pm 0.61$ \\
$10^{\circ}-20^{\circ}$ & $799 \pm 91$ & $1596 \pm 88$ & $2.0 \pm 0.44$ \\
$>40^{\circ}$ & $1467 \pm 189$ & $2534 \pm 284$ & $1.7 \pm 0.47$
\end{tabular}

Each value represents mean \pm SD for 15-20 measurements. 
parvo/magno ratio for different injection sizes

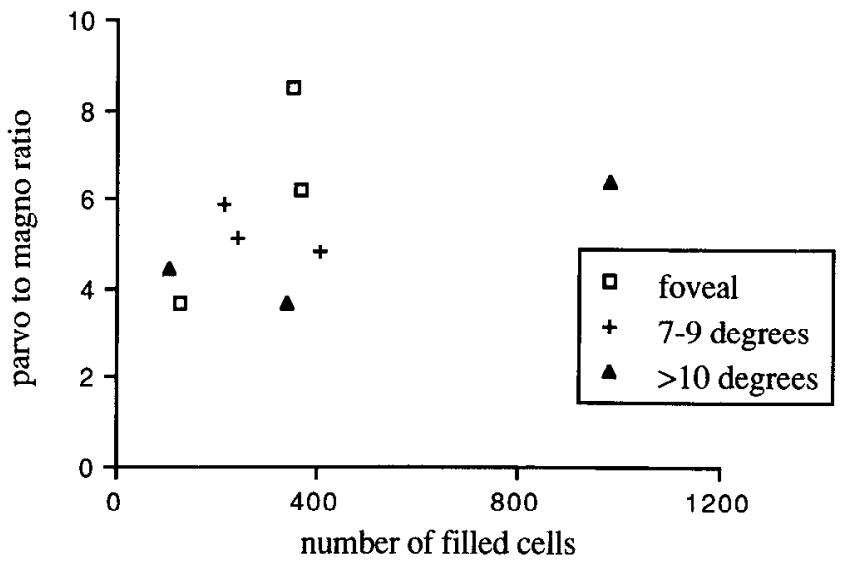

Figure 5. Parvo-to-magno ratios as a function of injection size (total number of filled geniculate cells). Data from Table 1 . While this suggests a tendency for the smaller injections to result in a lower ratio of parvoto magnocellular filled neurons, the effect is probably not enough to mask a 20 -fold difference between fovea and periphery.

not change significantly and certainly does not change by a factor of 20 between the foveal representation and $40^{\circ}$ eccentricity.

\section{Cortical sublaminae $4 C \alpha$ and $4 C \beta$}

To check Schein and de Monasterio's unpublished observation, and our own impressions, that there is no variation in the relative thickness of the magno- and parvorecipient subdivisions of layer $4 \mathrm{C}$, we compared the ratios of the thicknesses of the 2 sublaminae at several eccentricities from the fovea to the periphery. Our results are shown in Figure 3. Similarly, we found no significant change in the relative cell densities in $4 \mathrm{C} \alpha$ and $4 \mathrm{C} \beta$ with eccentricity; the cell density in $4 \mathrm{C} \beta$ was approximately twice that in $4 \mathrm{C} \alpha$ at all eccentricities.

\section{Discussion}

The results of the experiments described in this paper do not seem to be consistent with the idea that in going from the fovea to the far periphery the ratio in the retina or the geniculate of the number of cells/degree ${ }^{2}$ in the magno system to the cells/ degree $^{2}$ in the parvo system increases by as much as 20 times. In Figure 4 we compare our results and those of Perry et al. (1984) for Type A and B retinal ganglion cells with the predictions of Connolly and Van Essen and of Schein and de Monasterio.

To explain these large differences the first possibility to consider is that neither retrograde labeling of geniculate cells from Visual Area 1 nor the density of radioactive tracers transported from the eye to the cortex accurately reflects the relative mapping densities of the 2 systems. We assume that our HRP injections in Visual Area 1 covered equal areas in layers $4 \mathrm{C} \alpha$ and $4 \mathrm{C} \beta$ because they were all much larger than the thickness of laycr $4 \mathrm{C}$ and wcre roughly centered on it. There might nevertheless have been some systematic variation in the relative amounts of tracer transported by the 2 systems. Such a variation in tracer transport might arise from differences in the size of the cortical axonal arborizations of the 2 systems. Schein and de Monasterio argued that a shift from a changing magno-toparvo ratio in the geniculate to a constant ratio in the cortex should be reflected in significant variations in the relative lateral spread of the afferents in the 2 systems - that is, the ratio, be- tween the magno and parvo systems, of the areas of striate cortex contacted by a single geniculate afferents should vary 20 -fold between fovea and periphery. Florence and Casagrande (1987) found that in the prosimian galago the size of geniculocortical arborizations is 2- to 2.5-fold larger in the fovea than in the periphery, but ratio of the area of the magno to parvo arborizations nevertheless does not change with eccentricity, being 2.8 in the fovea and 2.3 in the periphery. In macaques there is also a difference between the magno and parvo systems in the size of the axonal aborizations (Blasdel and Lund, 1983), but so far there is no evidence on whether this difference varies with eccentricity. If it did, then the effective injection size should indeed be different for the magno and the parvo systems, and the difference between the 2 should vary with eccentricity. This effect should be more important the smaller the injections, and it would give erroneously low parvo-to-magno ratios for small injections. But, as shown in Figure 5, although there may be some tendency for the parvo-to-magno ratio to vary with the total number of back-filled cells, which should be proportional to injection size, the variation is probably not enough to have masked a 20 -fold difference between fovea and periphery.

For the interpretation of the eye-injection results, any systematic difference in relative arborization size would not seem to be a problem. We do not know what determines the amount of radioactivity transported from any given part of the retina to the cortex, though it seems likely that the most important factors would be the size of ganglion cells and the area of cortex to which they project. Variations in ganglion-cell size and axon diameter, with eccentricity and between magno- and parvoprojecting subclasses, as well as differences in chronic activity levels (and consequent differences in amino acid usc), could also affect the ultimate amount of radioactivity transported by different axons to different parts of the cortex. Nevertheless, the 4-fold higher grain density in the periphery over the fovea for both sublaminae of layer $4 \mathrm{C}$ suggests that grain density in the cortex may, in fact, be directly proportional to the number of retinal ganglion cells mapping onto a given cortical area and gives us some confidence that the small difference between the fovea and the periphery in the ratio of magno to parvo grain densities does indicate that the 2 systems do not differentially change much with eccentricity in their retinogeniculocortical mapping. The fact that, at the 4 eccentricities examined, the ratio of grain densities in $4 \mathrm{C} \beta$ to $4 \mathrm{C} \alpha$ was lower than the ratio of retrogradely labeled cells may reflect better transport by the larger cells in the magno system.

\section{Is the conclusion correct that the magno and parvo systems differentially vary in their geniculocortical mapping functions?}

The evidence for the idea that the fovea is 10 - to 20 -fold underrepresented in the magnocellular layers of the geniculate depends ultimately on a topographic map of the geniculate calculated by Connolly and Van Essen (1984) from data of Malpeli and Baker (1975) and Le Gros Clark (1941). The calculation involves at least 4 remappings or reconstructions. Malpeli and Baker determined visual-field positions along vertical electrode penetrations in one lateral geniculate body and made electrolytic lesions to mark electrode positions. They then used the positional information from the electrolytic lesions and depth measurements to map the visuotopic information onto coronal histological sections of the same geniculate, corrected for differential shrinkage. Connolly and Van Essen converted these maps into representations of horizontal sections. They then converted the 
maps of horizontal sections into planar 2-dimensional maps of each of the layers using a manual method of aligning and adjusting tracings of serial sections (Van Essen and Maunsell, 1980). Then, in order to calculate how many cells in each layer represent a given area of the visual field, they needed to know the number of cells across each layer. To get this value they combined their own measurements of layer thickness in 3 other geniculates with laminar cell density measurements made by Le Gros Clark in 1941 from coronal sections of yet another monkey. They then combined these numbers with the planar visuotopic maps of each layer that they had calculated from Malpeli and Baker's data.

At least 2 of these calculations seem to us to be potential sources of significant errors. First, the representation of the layers as flat sheets, if they are really dome-shaped, would introduce distortion, especially at the edges, and the foveal representation is along the posterior edge. Connolly and Van Essen say, however, that their flattening procedure introduced at most $30 \%$ linear distortion. The other questionable part of the calculation is the combining of cell-density measurements from Le Gros Clark, layer thickness measurements from their own data, and visuotopic maps from Malpeli and Baker. This seems to us to involve the integration of data from too many different laboratories and too many different monkeys to be likely to be accurate. For example, Le Gros Clark's data are from a geniculate half as large (after fixation) as the one mapped by Malpeli and Baker. Moreover, Malpeli and Baker found so much differential shrinkage that their vertical needle marks all fanned out from the hylum, indicating $25 \%$ more shrinkage in the magnocellular layers than in the parvocellular layers, and the amount of shrinkage varied with eccentricity (J. G. Malpeli, personal communication). They themselves did not think it would be useful to compare their own results with Le Gros Clark's; "since he did not consider the possibility of differential shrinkage we hesitate to use these data quantitatively."

Thus, despite the evident rigor of these calculations, we worry about the number of steps involved and the indirectness of the deductions. Though the interpretation of our data is subject to the caveats mentioned above, our results and the results of Perry, Oehler, and Cowey are enough to make us seriously question the contention that betwen the fovea and the far periphery there is a 20 -fold change in the relative mapping densities of the magno and parvo systems onto the visual cortex; indeed, there may be no change at all. We did these experiments to see if they would support this idea, and they did not. To resolve the issue satisfactorily would require a careful comparison of Type A to Type B retinal ganglion cells in the fovea, detailed receptive field maps of each geniculate layer and cell densities measured in the same geniculate, and more cortical HRP injections, of varying sizes. For the present, costs, time, and the number of animals required make us hesitate to pursue these questions further.

\section{References}

Blasdel, G. G., and J. S. Lund (1983) Termination of afferent axons in macaque striate cortex. J. Neurosci. 3: 1389-1413.
Connolly, M., and D. C. Van Essen (1984) The representation of the visual field in parvicellular and magnocellular laminae of the lateral geniculate nucleus in the macaque monkey. J. Comp. Neurol. 226: 544-564.

Daniel, P. M., and D. Whitteridge (1961) The representation of the visual field of the cerebral cortex in monkeys. J. Physiol. (Lond.) 159: 203-221.

Fendick, M., and G. Westheimer (1983) Effects of practice and the separation of test targets on foveal and peripheral stereoacuity. Vision Res. 23: 145-150.

Florence, S. L., and V. A. Casagrande (1987) Organization of individual afferent axons in layer IV of striate cortex in a primate. $J$. Neurosci. 7: 3850-3868.

Hanker, J. S., P. E. Yates, C. B. Metz, and A. Rustioni (1977) A new specific sensitive and non-carcinogenic reagent for the demonstration of horseradish peroxidase. Histochem. J. 9: 789-792.

Hubel, D. H., and D. C. Freeman (1977) Projection into the visual field of ocular dominance columns in macaque monkey. Brain Res. 122: 336-343.

Hubel, D H., and T. N. Wiesel (1972) Laminar and columnar distribution of geniculocortical fibers in the macaque monkey. J. Comp. Neurol. 146: 421-450.

Le Gros Clark, W. E. (1941) The laminar organization and cell content of the lateral geniculate body in the monkey. J. Anat. 75: 419-433.

Le Vay, S., M. Connolly, J. Houde, and D. C. Van Essen (1985) The complete pattern of ocular dominance stripes in the striate cortex and visual field of the macaque monkey. J. Neurosci. 5: 486-501.

Leventhal, A. G., R. W. Rodieck, and B. Dreher (1981) Retinal ganglion cell classes in old-world monkey: Morphology and central projections. Science 213: 1139-1142.

Livingstone, M. S., and D. H. Hubel (1987) Psychophysical evidence for separate channels for the perception of form, color, movement and depth. J. Neurosci. 7: 3416-3468.

Lund, J. S. (1987) Local circuit neurons of macaque monkey striate cortex: I. Neurons of laminae 4C and 5A. J. Comp. Neurol. 257: 6092.

Malpeli, J. G., and F. H. Baker (1975) The representation of the visual field in the lateral geniculate nucleus of Macaca mulatta. J. Comp. Neurol. 161: 569-594.

McKee, S. P., and K. Nakayama (1984) The detection of motion in the peripheral visual field. Vision Res. 24: 25-32.

Mesulam, M.-M. (1982) Principles of horseradish peroxidase neurohistochemistry and their applications for tracing neural pathwaysAxonal transport, enzyme histochemistry and light microscopic analysis. In Tracing Neural Connections with Horseradish Peroxidase, M.-M. Mesulam, ed., pp. 1-151, Wiley, New York.

Perry, V. H., R. Oehler, and A. Cowey (1984) Retinal ganglion cells that project to the dorsal lateral geniculate nucleus in the macaque monkey. Neuroscience 12: 1101-1123.

Schein, S. J. (1988) Anatomy of macaque fovea and spatial densities of neurons in foveal representation. J. Comp. Neurol. 269: 479-505.

Schein, S. J., and F. M. de Monasterio (1987) Mapping of retinal and geniculate neurons onto striate cortex of macaque. J. Neurosci. 7; 996-1009.

Tootell, R. B. H., M. S. Silverman, E. Switkes, and R. L. De Valois (1982) Deoxyglucose analysis of retinotopic organization in primate striate cortex. Science 218: 902-904.

Van Essen, D. C., and J. H. R. Maunsell (1980) Two-dimensional maps of the cererbral cortex. J. Comp. Neurol. 191: 255-281.

Van Essen, D. C., W. T. Newsome, and J. H. R. Maunsell (1984) The visual field representation in striate cortex of the macaque monkey: Asymmetries, anisotropics, and individual variability. Vision Res. 24: 429-448.

Westheimer, G. (1982) The spatial grain of the perifoveal visual field. Vision Res. 22: 157-162.

Wong-Riley, M. T. T. (1979) Changes in the visual system of monocularly sutured or enucleated cats demonstrable with cytochrome oxidase histochemistry. Brain Res. 171: 11-28. 